\title{
ASSESSMENT OF TFP IN EUROPEAN AND AMERICAN HIGHER EDUCATION INSTITUTIONS - APPLICATION OF MALMQUIST INDICES
}

\author{
Joanna WOLSZCZAK-DERLACZ \\ Faculty of Management and Economics, Gdansk University of Technology, \\ Narutowicza 11/12, 80-233 Gdańsk, Poland
}

Received 09 March 2015; accepted 06 February 2016

\begin{abstract}
In this study we apply Malmquist methodology, based on the estimation of distance measures through Data Envelopment Analysis (DEA), to a sample of 500 universities (in 10 European countries and the U.S.) over the period 2000 to 2010 in order to assess and compare their productivity. On average, a rise in TFP is registered for the whole European sample (strongest for Dutch and Italian HEIs), while the productivity of American HEIs suffered a slight decline. Additionally, we show that productivity growth is negatively associated with size of the institution and revenues from government, and positively with regional development in the case of the European sample, while American HEI productivity growth is characterised by a negative association with GDP and a positive one with the share of government resources out of total revenue.
\end{abstract}

Keywords: total factor productivity, higher education, Malmquist index, DEA, nonparametric methods.

JEL Classifications: I23, H52, C14.

Online supplementary material: Supporting information for this paper is available as online supplementary material at http://dx.doi.org/10.3846/20294913.2016.1213197

\section{Introduction}

Assessment of the performance of higher education institutions (hereafter, HEIs) is a very complex and challenging task. This is probably due to the characteristics of the education market - universities are mostly non-profit institutions that are involved in various activities (teaching, research and other services for the community), and their outcomes are difficult to measure. The production which takes place in the higher education sector differs from the normal production cycle: it has a multiplicity of inputs and outputs, the relationships between which are often bidirectional and under the influence of external factors, including strong state regulation. Therefore, the traditional indicators used in the

Corresponding author Joanna Wolszczak-Derlacz

E-mail: jwo@zie.pg.gda.pl 
economic analysis of enterprises (e.g. profit maximization) cannot be applied in this case, and to evaluate the efficiency and productivity of individual institutions requires more sophisticated tools of analysis such as non-parametric methods (Akviran 2001).

In spite of the difficulties in measuring the outcomes of HEIs well, their efficiency and productivity is of interest not only to HEI managers but also to students, academic staff, non-academic employers, and finally policy makers. In recent years, more attention has been given to the rational use of public resources (mainly due to the economic crisis), including the problem of the efficient use of financial and labour resources by universities (Bonaccorsi et al. 2007). The need to provide an efficient and productive higher education system is stressed both by European and American leaders. For example, the aim of the EU Lisbon strategy (and its continuation "Europe 2020") is to make the EU the most competitive and dynamic knowledge-based economy, with an undoubted role for higher education, while recent American reforms stress the problem of cost efficiency (e.g. due to increasing tuition fees), which in turn hampers student attainment ${ }^{1}$.

In this study, we apply Malmquist methodology based on the estimation of distance measures through Data Envelopment Analysis (hereafter, DEA) to a sample of 500 universities over the period 2000 to 2010 in order to assess and compare their productivity. There is a growing body of research dedicated to assessing the efficiency of HEIs through the use of non-parametric methods (DEA and Malmquist indices), mainly based on internal (country-specific) experience (for some early reviews, see Worthington (2001) and Johnes (2004); recent studies have been surveyed, e.g., by Brennan et al. (2014) and Nazarko and Šaparauskas (2014) $)^{2}$. Little research has, however, been devoted to productivity and efficiency measurement from an international perspective, and even fewer studies are dedicated to the development of efficiency and productivity over periods of years. This is probably the result of data collection difficulties at the level of individual institutions. Two countries (Italy and UK) are analyzed by Agasisti and Johnes (2009). They compare productivity changes in HEIs between 2002/03 and 2004/05 and find a stronger improvement in Italian performance. This is confirmed by Agasisti and Pérez-Esparrells (2010), who this time compare Italian institutions to Spanish ones. They find that between the academic years 2000/2001 and 2004/2005 the average total factor productivity of Italian universities increased by $48 \%$, while in Spain the increase was only 6\% (the Malmquist index is 1.48 vs. 1.06). Finally, Agasisti and Pohl (2012) perform a similar exercise for Italian and German HEIs. They observe substantial total factor productivity (TFP) progress in both countries over the period 2001-2007. To the best of out knowledge, Parteka and Wolszczak-Derlacz (2013) is the only study that analyses productivity changes for more than two countries as the present paper does. They examine patterns of productivity change in a set of $266 \mathrm{HEIs}$ in 7 European countries over the time period 2001-2005. They conclude that HEI productivity rose on average by $4 \%$ annually with statistically significant changes in productivity registered in $90 \%$ of the observations and $56 \%$ of all cases experiencing statistically signifi-

\footnotetext{
${ }^{1}$ Reform of the higher education sector announced by president Barack Obama in August 2013 with the aim of increasing affordability for students and accountability for colleges (see more at: http://www.whitehouse.gov/issues/ education/reform).

2 Since our paper concentrates on international and inter-temporal analyses, we do not refer directly to countryspecific studies, but we rather focus on cross-country analysis. Panagiotis (2014) in his meta-analysis of productivity growth in HEIs (with the application of Malmquist indices) lists 28 studies dedicated to this topic. However, only 4 studies have a cross-country character.
} 
cant annual improvements in productivity. Statistical significance is assessed by means of bootstrap estimations. They also underline considerable national differences, with German, Italian and Swiss HEIs performing better in terms of productivity change than HEIs from the other countries examined (Poland, Finland, the UK and Austria). However, unlike the present paper, none of these studies compare European HEIs with their U.S. counterparts or examine the source of productivity changes.

This study has three aims. Firstly, it conducts a time-series analysis to contrast total factor productivity (hereafter, TFP) changes in European and U.S. higher education institutions. Secondly, the Malmquist indices are decomposed into pure efficiency and technology effects (catching up versus frontier shifts). The third aim is to investigate the main sources of productivity changes and to test whether these factors might have varying impacts on changes in European and U.S. productivity. As far as methodology is concerned, we provide a statistical analysis with the use of bootstrap techniques, which makes it possible to assess the statistical significance of Malmquist indices. Their lack of statistical interference is usually considered a basic drawback of non-parametric methods.

The policy implications of this study are straightforward. Provision of an understanding of performance changes together with their determinants provides valuable information for managers and stakeholders in individual HEIs, as well as aiding the efficient orientation of education policies.

The structure of the paper is as follows. A brief sketch of the methodology is presented in Section 1 below. Section 2 contains a description of the data, and the results of the empirical analysis are presented in Section 3. The last Section outlines the main policy implications, and is followed by some concluding remarks.

\section{Methodology}

In the empirical part of this study, the productivity changes of given HEIs between two periods of time will be evaluated by means of Malmquist indices, based on estimation of distance functions through non-parametric DEA methodology. A DEA-based Malmquist productivity index was developed by Färe et al. $(1992,1994)$, who combined the concept of efficiency measurement in Farrell (1957) with the productivity measurement in Caves et al. (1982). In this way, calculation of a Malmquist productivity index is directly possible from input and output data using DEA. If we describe the activity of a given decision-making unit (hereafter, DMU) by the production set $\Psi$ of physically possible points $(x, y)$ :

$$
\Psi^{t}=\left\{\left(x_{t}, y_{t}\right): \mid x_{t} \text { can produce } y_{t}\right\}
$$

where $x$ represents a vector of $N$ inputs and $y-$ a vector of $M$ outputs in period $t$. The Malmquist index is then computed as the geometric mean of two indices: the first with period $t_{1}$ being the reference technology; the second with period $t_{2}$ being the reference:

$$
M I_{i,\left(t_{1}, t_{2}\right)}=\left[\frac{D_{i}^{t_{1}}\left(x_{t_{2}}, y_{t_{2}}\right)}{D_{i}^{t_{1}}\left(x_{t_{1}}, y_{t_{1}}\right)} * \frac{D_{i}^{t_{2}}\left(x_{t_{2}}, y_{t_{2}}\right)}{D_{i}^{t_{2}}\left(x_{t_{1}}, y_{t 1}\right)}\right]^{1 / 2},
$$

where $\mathrm{D}_{\mathrm{i}}$ refers to the distance function of the given DMU $i$, and $\mathrm{x}$ and $\mathrm{y}$ are inputs and 
outputs as before, now related to two periods of time: $t_{1}$ and $t_{2}$. The output distance functions (distance between an observation and the boundary) are calculated as the inverse of Farrell (1957) technical efficiency. For example, in the case of output efficiency by keeping the inputs fixed and increasing the outputs:

$$
D_{i}^{t_{1}}\left(x_{t, i}, y_{t, i}\right)^{-1}=\left(\sup \left\{\theta \mid\left(x_{t, i}, \theta y_{t, i}\right) \in \Psi^{t_{1}}\right\}\right), t=t_{1}, t_{2} .
$$

The output distance function $\left(D_{i}^{t_{2}}\right)$ is computed analogously with respect to $t_{2}-$ technology. If we have data on the inputs $x_{t, i}=\left(x_{t, i 1}, \ldots, x_{t, i n}, \ldots x_{t, i N}\right)$ and outputs $y_{t, i}=\left(y_{t, i 1}, \ldots, y_{t, i m}, \ldots y_{t, i M}\right)$ of a given firm (i.e. university) $i(i=1, \ldots, L)$, the distance function can be found by linear programming:

$$
\begin{array}{ll} 
& \hat{D}_{i}^{t_{1}}\left(x_{t, i}, y_{t, i}\right)^{-1}=\max \theta ; \\
\text { s.t. } & \theta y_{t_{1}, i m} \leq \sum_{j=1}^{L} \lambda_{t_{1}, j} y_{t_{1}, m j}, \quad(\vee m \in M) ; \\
& \sum_{j=1}^{L} \lambda_{t_{1}, j} x_{t_{1}, j n} \leq x_{t_{1}, i n}, \quad(\vee n \in N) ; \\
& \lambda_{t_{1}, i} \geq 0, \quad(\vee i \in L),
\end{array}
$$

where $\lambda_{t_{1}}=\left(\lambda_{t_{1}, 1}, \ldots, \lambda_{t_{1}, L}\right)$ are the non-negative weights that form a convex combination of observed firms relative to which the subject firm's efficiency is evaluated. In model (4) we apply constant returns to scale (hereafter, CRS) in order to interpret the Malmquist index as a total factor productivity change, which is only possible if we base the efficiency measures on comparing the observations with the corresponding optimal scale points. ${ }^{3}$

A value of the MI greater than one indicates positive TFP growth; an MI smaller than one is a sign of TFP decline; when MI = 1 then a conclusion of no productivity change is reached. According to Färe et al. (1992, 1994), a Malmquist index can be decomposed into two components: a pure efficiency change (TE) - the movement of a given DMU towards or away from the frontier - and a technology change (TT) - a frontier shift:

$$
\mathrm{MI}_{i,\left(t_{1}, t_{2}\right)}=\frac{D_{i}^{t_{2}}\left(x_{t_{2}}, y_{t_{2}}\right)}{D_{i}^{t_{1}}\left(x_{t_{1}}, y_{t_{1}}\right)} *\left[\frac{D_{i}^{t_{1}}\left(x_{t_{2}}, y_{t_{2}}\right)}{D_{i}^{t_{2}}\left(x_{t_{2}}, y_{t_{2}}\right)} * \frac{D_{i}^{t_{1}}\left(x_{t_{1}}, y_{t_{1}}\right)}{D_{i}^{t_{2}}\left(x_{t_{1}}, y_{t_{1}}\right)}\right]^{1 / 2} \text {. }
$$

(TE)

This decomposition can be important for an assessment of the main determinants of productivity changes, e.g. in order to test whether universities are catching up with the leading ones or whether the whole sector has undergone a major development.

The statistical properties of the MI and its components are obtained by means of a bootstrap procedure following Simar and Wilson (1999), which involves the generation of pseudo-data and approximating the unknown distribution of efficiency scores using

\footnotetext{
${ }^{3}$ As explained in the literature, this assumption refers to CRS technology enveloping the actual VRS technology (Førsund, Kalgahen 1999: 12).
} 
the distribution of bootstrap values. Once bootstrap estimates of distance functions are calculated, they are used to construct a bootstrap Malmquist index and its components (using Eqs. (2) and (5)). The bootstrap Malmquist index is used to calculate a bias-corrected estimator (Simar, Wilson 1999: 463):

$$
\widehat{\widehat{M I}}_{i,\left(t_{1}, t_{2}\right)}=2 \widehat{\mathrm{MI}}_{i,\left(t_{1}, t_{2}\right)}-B^{-1} \sum_{b=1}^{B} \widehat{\mathrm{MI}}_{i,\left(t_{1}, t_{2}\right)(b)}^{*},
$$

where $B$ is the number of bootstrap replications and $\widehat{M}_{i,\left(t_{1}, t_{2}\right)(b)}^{*}$ are the bootstrap indices. The bias-corrected indices are employed as long as their mean square errors (MSE) are lower than the MSEs of the original estimates. Finally, estimation of confidence intervals makes it possible to draw a conclusion about the statistical significance of total factor productivity (TFP) changes. A (1- $\alpha)$ percent confidence interval can be expressed as:

$$
\widehat{\mathrm{MI}}_{i,\left(t_{1}, t_{2}\right)}+a_{\alpha}^{*} \leq \mathrm{MI}_{i,\left(t_{1}, t_{2}\right)} \leq \widehat{\mathrm{MI}}_{i,\left(t_{1}, t_{2}\right)}+b_{\alpha}^{*},
$$

where $a_{\alpha}{ }^{*}$ and $b_{\alpha}{ }^{*}$ respectively define the lower and upper bootstrap estimates of confidence interval bounds for the Malmquist index and $\alpha$ (e.g. 10\%, 5\% or 1\%). Changes in TFP are statistically significant if the interval (7) does not include unity (remember that MI $=1$ indicates no productivity changes). The whole procedure (Eqs. (6) and (7)) can be repeated for the components of the MI - technical efficiency and technology - with an analogous interpretation of their statistical significance. All the calculations are carried out with the use of FEAR 1.15 software (Wilson 2008).

\section{Data and panel composition}

Regarding the comparison between US and European higher education, the basic characteristics of the former include: size (20 million students, 4706 degree-granting institutions ${ }^{4}$ ), reputation (eight of the top ten universities are in the US, according to the AWRU Shanghai ranking ${ }^{5}$ ), and a high level of autonomy, decentralisation and differentiation. Altbach et al. (2011) describe the autonomy of US HEIs in terms of three freedoms: the freedom of universities to select staff and students, their freedom to determine curriculum content and degree standards, and the freedom to allocate funds across different categories of expenditure (in accordance with the rules of law and accountability). European education institutions, on the contrary, are generally much more dependent on central or regional governments.

A second key difference relates to sources of funding. In the US, HEIs are characterized by financial diversification. For example, in the academic year 2011/2012 around 23.5\% of total public institution revenue came from state governments, $20.6 \%$ from tuition fees, $17.5 \%$ from the federal government (in the form of operating grants and contracts, funds

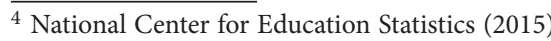

${ }^{5}$ www.shanghairanking.com/ARWU2014.html
} 
for independent operations, non-operating revenue appropriations, and non-operating grants), and $13.6 \%$ in the form of investment returns, gifts, and other (National Center for Education Statistics 2015: 385). Tuition fees are paid at public and private institutions, e.g. the average undergraduate fee for full-time students in degree-granting post-secondary public institutions was 5899 USD in 2012/2013 and 23943 USD in private ones. In European countries, there is much variation in the numbers of students paying fees in publically-funded higher education institutions. In the Nordic countries there are no tuition fees; in Slovenia and Poland fees are only paid by part-time students, and in the UK all 1st cycle students pay fees (the specific regulations concerning tuition fees in each European country are described, e.g., in Eurydice 2015).

The final specific characteristic of American HEIs is competition in almost all aspects of university activity: universities compete for professors, students, administrators and funds (Aguilera-Barchet 2012). According to a study performed by Aghion et al. (2010), universities are more productive when they are both more autonomous and face more competition.

Generally, a higher education system consists of public and private institutions (in the U.S., for example, the latter can be further divided into private for profit and private not for profit institutions). Public and private HEIs are usually subject to different national regulations - e.g. concerning obtaining governmental subsidies - and often specialise in different activities (e.g. in Europe, public universities are more research-oriented than their private counterparts). Due to these above-mentioned differences we focus on public institutions in this study.

Our final dataset consists of information on 500 HEIs in 10 European countries and the U.S. for the period 2000-2010, which is the result of a trade-off between the number of countries/institutions in the sample, the number of variables and the years covered. For example, HEIs which were not in continuous existence over the sample period are dropped (need for a balanced panel) ${ }^{6}$. Most of the information (e.g. about total financial resources, a breakdown of resources into sources, the number of academic and non-academic staff, students etc.) comes from different national sources, mainly ministries of higher education (Austria, Poland, Finland), central statistical offices (Germany, Switzerland) and specific educational or statistical agencies e.g. the Association of Universities in the Netherlands (VSNU), the Spanish Rectors Conference (CRUE), the National Agency for the Evaluation of Universities (ANVUR) in Italy, the Higher Education Statistics Agency in the UK and the Integrated Postsecondary Education Data System (IPEDS) for American HEIs. Collection of the data follows the UNESCO-UIS/OECD/Eurostat, 2004 data collection manual and

\footnotetext{
${ }^{6}$ One possible way of balancing an unbalanced panel when calculating Malmquist indices is based on the creation of fake units, as demonstrated by Yang and Pollitt (2012). However, they admit that the use of a fake unit influences the final calculation of Malmquist indices, e.g. in the case of a unit which is shut down in a reported year, because the real observations are used up to the reported year (as a result, a sharp decrease in productivity is observed in the reported year) and analogously in the case of a unit which is newly established in a reported year (a large productivity increase in that year). Because of these problems, we decided to stick to real observations (without the creation of fake units, which can, in fact, also influence the calculation of the Malmquist indices of other units). We thank an anonymous referee for pointing out this possibility of balancing an unbalanced panel.
} 
the Frascati manual (OECD 2002) in order to guarantee a maximum level of comparability of the crucial variables across countries ${ }^{7}$.

Table 1 provides some basic information on the HEIs in our sample. European and American institutions are characterised by similar numbers of academic staff and students per institution (e.g. in 2000 the average number of academic staff in the European sample was 1 276, and 1308 in the U.S., while student numbers were around 19000 per institution both in Europe and the U.S., which gives around 15 students per academic staff member in both continents) while the average number of graduates is considerable higher in the U.S. institutions. This dichotomy is expressed in higher values of the ratio of graduates to academic staff in the case of American HEIs. A very particular feature of our dataset is its multi-year dimension, which allows us to observe changes in the variables over time. The lower panel of Table 1 presents the analogous information for 2010. For example, European institutions have reduced differences in the ratio of graduates to academics in relation to their American counterparts. This was probably possible due to the introduction of the Bachelor/Master degree structure in the EU as one of the results of the Bologna process (Agasisti, Pérez-Esparrells 2010).

In the next section, we treat the number of graduates as the teaching output and publication as a proxy of research output. We limit publications to those listed in Thomson Reuters' ISI Web of Science database (part of the ISI Web of Knowledge), which lists publications from quality journals in all scientific fields. We count all publications (scientific articles, proceedings papers, meeting abstracts, reviews, letters, notes, etc.) published in a given year with at least one author declaring he/she is an affiliate of the HEI institution under consideration. In this context, the ratio of publications per academic staff member can be viewed as a partial productivity measure. Similarly to the measure of teaching productivity (graduates per academic staff), the measure of research productivity is on average smaller for European institutions than for American ones (0.53 compared to 0.91 in 2000, and 0.74 to 1.13 in 2010). However, here (as well as in other statistics) there is significant heterogeneity across European countries and also within countries (note the values of the standard deviation of the given variables - reported in parenthesis in Table 1).

When we talk about the assessment of HEI performance, the crucial aspect is their level of finance. Overall, the U.S. universities have many more resources than their European counterparts over the whole period of time. There is a slight increase in revenue per student - shown in Figure 1 - (as well as in revenue per academic staff member, which is not presented here) for both the U.S. and European institutions. However, the trend is not common to all European countries; specifically, in Italy, the Netherlands and Sweden there is a drop in the ratio.

\footnotetext{
7 We are aware of potential limitations of this study, in particular connected with the selection of the sample data and comparability issues. As usual in such cross-countries studies (see e.g. Agasisti and Johnes (2009); Agasisti and Pérez-Esparrells (2010); and Wolszczak-Derlacz and Parteka (2011)), when one common database does not exist (e.g. at the European level) the comparability of data can be problematic. However, we have put extreme efforts into ensuring the correspondence and reliability of the data, in particular by following the Unesco-UIS/ OECD/Eurostat, 2004 data collection manual and the Frascati manual (OECD 2002). In addition, we use bootstrap technique to assess the statistical significance of changes in the productivity. The bootstrap procedure deals with the issue of sampling variability and reduces the problems which would otherwise be encountered with DEA/ Malmquist without using the population of data. Nevertheless, being aware of the limitations of data, the results should be interpreted very carefully. We thank an anonymous referee for pointing this out.
} 


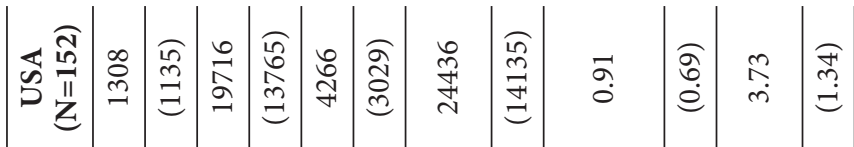

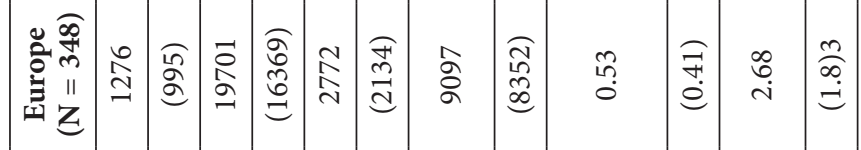

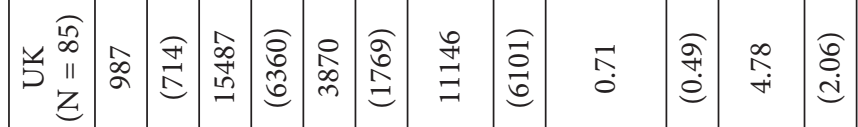

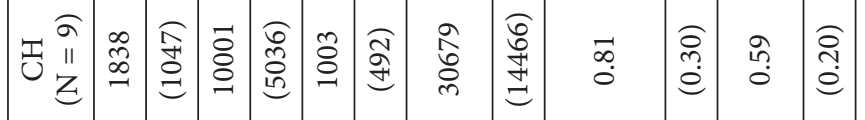

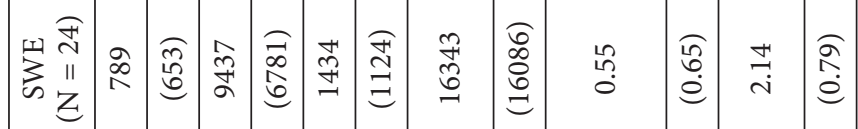

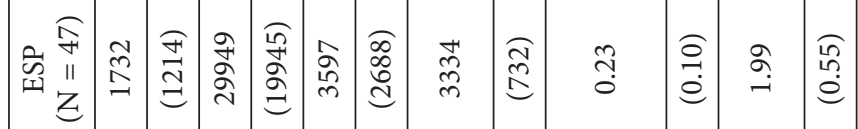

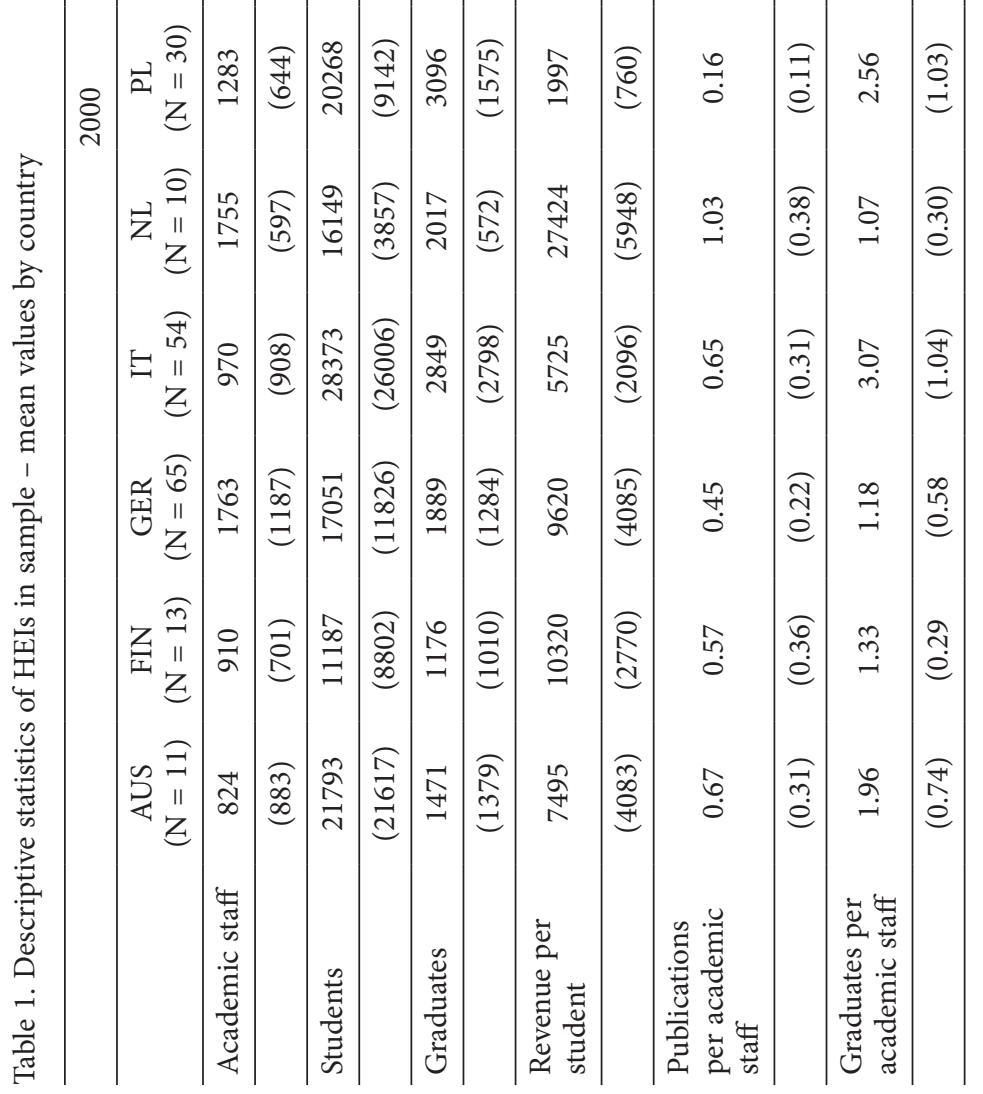




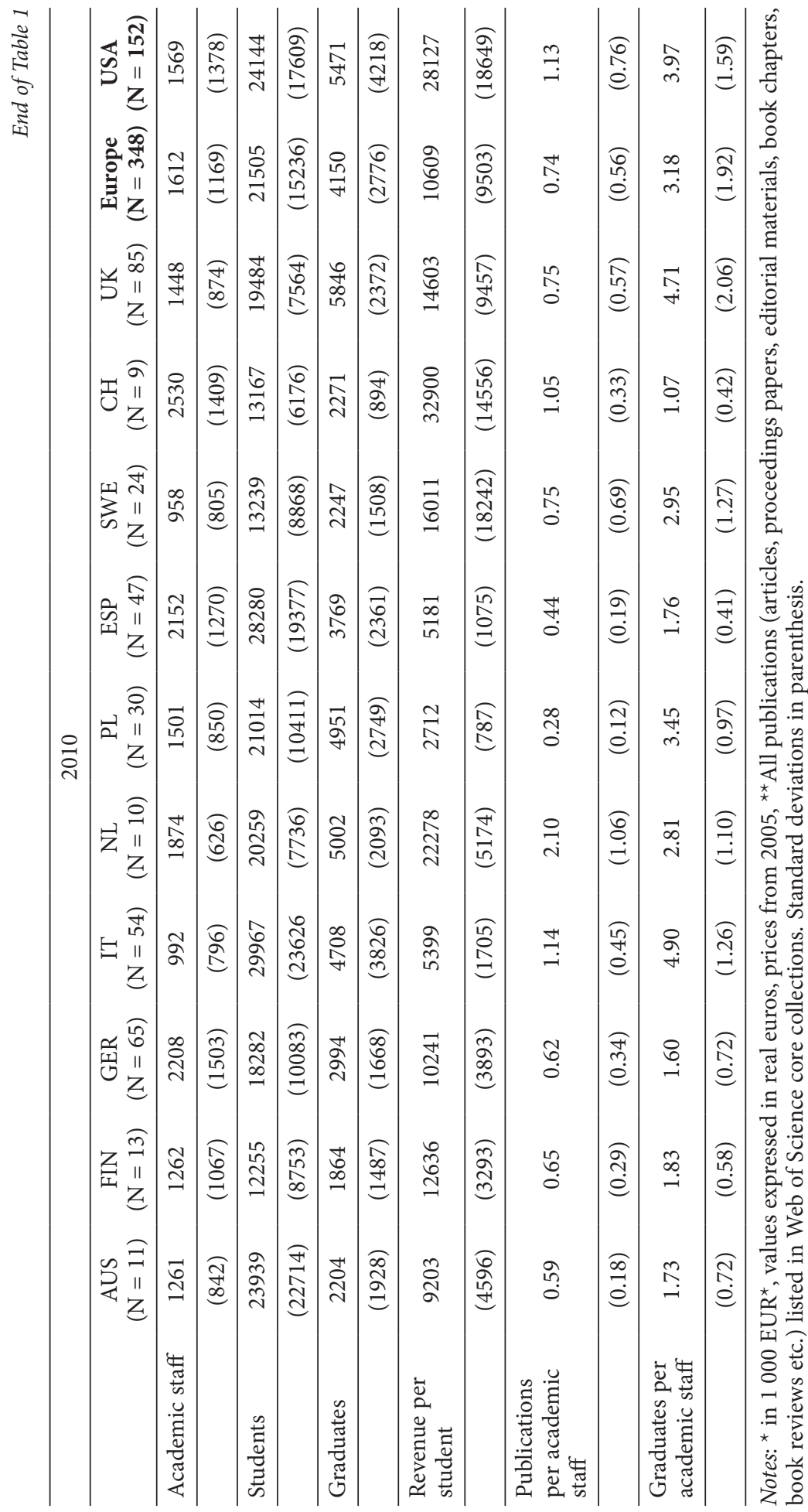


Figure 2 presents changes in the share of revenue coming from government sources. In both groups there is a decline in this percentage (in the U.S. the drop is much more pronounced). This drop in the share of revenue from government sources is accompanied by an increase in the revenue from tuitions fees (from $20 \%$ to $29 \%$ for the U.S. and from $12 \%$ to $23 \%$ for European HEIs).

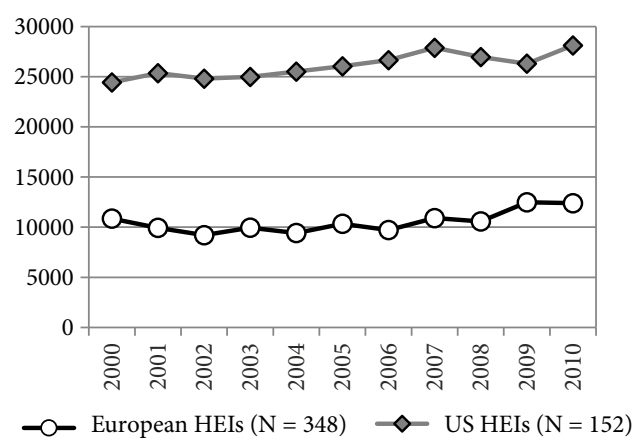

Fig. 1. Revenue per student in real euros (2000-2010), European versus U.S. HEIs Source: authors' elaboration.

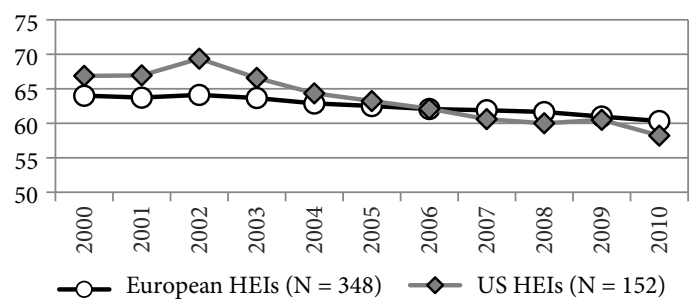

Fig. 2. The share of revenue from government funding (2000-2010), European versus U.S. HEIs Source: authors' elaboration.

We must remember that the period on which we focus (2000-2010) was a time of deep changes in HEI financing, mainly due to a shortage of public resources as a result of the 2007/2008 crisis.

These changes in absolute and relative resources undoubtedly impacted on the institutions' performance. In a second step of our analysis we will examine how this changed revenue structure influenced productivity changes.

\section{Assessment of changes in productivity over time}

\subsection{Malmquist indices}

In order to calculate Malmquist indices and their components for every institution and year in the sample analysed, we have to specify DEA models. Careful choice of the input/ output mix is the critical point in efficiency assessment with non-parametric methods such as DEA and Malmquist indices. Although we are restricted by data availability, we closely follow previous studies in this respect and the final input/output set is well justified. As a 
robustness check, we calculate DEA models with three different input/output compositions (Table 2 presents descriptions of the DEA models). Our basic model is based on three inputs and two outputs. As inputs we use total revenue (real values expressed in prices from 2005 and converted to euros), the number of academic staff and the number of students. The outputs consist of the number of publications indexed in the Web of Science (proxy for research activity) and the total number of graduates (measure of teaching activity). A similar set of input/output mixes has been used in some recent studies, e.g. by Parteka and Wolszczak-Derlacz (2013) and Bonaccorsi et al. (2014).

Table 2. DEA model input/output specifications

\begin{tabular}{|c|c|c|c|}
\hline & Frontier & Inputs & Outputs \\
\hline Model 1 & \multirow{3}{*}{$\begin{array}{l}\text { Common } \\
\text { frontier (all } \\
\text { HEIs pooled } \\
\text { together) }\end{array}$} & $\begin{array}{l}\text { Total revenue, } \\
\text { academic staff, total students }\end{array}$ & Publications, graduates \\
\hline Model 2 & & Total revenue, academic staff & Publications, graduates \\
\hline Model 3 & & $\begin{array}{l}\text { Total revenue, academic staff, } \\
\text { Administration staff, total students }\end{array}$ & $\begin{array}{l}\text { Articles, publications other than } \\
\text { articles, graduates }\end{array}$ \\
\hline Model 4 & \multirow{3}{*}{$\begin{array}{l}\text { Regional } \\
\text { frontier } \\
\text { - (European/US } \\
\text { frontier) }\end{array}$} & $\begin{array}{l}\text { Total revenue, academic staff, } \\
\text { total students }\end{array}$ & Publications, graduates \\
\hline Model 5 & & Total revenue, academic staff & Publications, graduates \\
\hline Model 6 & & $\begin{array}{l}\text { Total revenue, academic staff, } \\
\text { administration staff, total students }\end{array}$ & $\begin{array}{l}\text { Articles, publications other than } \\
\text { articles, graduates }\end{array}$ \\
\hline
\end{tabular}

Next, we need to define the frontier. Because one common frontier and one common technology for the whole sample of HEIs could be too restrictive, we alternatively also calculate the efficiency measures with the assumption of separate frontiers for European and U.S. institutions. In the DEA specification we decide to stick to constant returns to scale (CRS) in order to be able to interpret the Malmquist indices as total factor productivity changes (Førsund, Kalgahen 1999).

Due to the multi-year dimension of the dataset we calculate the Malmquits indices and their components for every institution and for two-year intervals (indices for 2000-2001, 2001-2002, 2002-2003 etc.) in the sample. If the Malmquist index (MI) equals one, it represents no change in productivity; a value greater than one indicates positive TFP growth; and an MI smaller than one indicates a TFP decline. Table 3 presents the average annual changes in $\mathrm{TFP}^{8}$ based on the original Malmquist indices ${ }^{9}$ for the 11 countries analysed, both for the common frontier and for the European and US ones. The mean values are only calculated on the basis of statistically significant indices (however, the percentage of statistically significant indices is high - ranging from $77 \%$ for all the indices in the Netherlands and 90\% in Austria; see Table A1 in the Appendix). The statistical significance reflects

\footnotetext{
8 The detailed results for all 500 HEIs and all the years of analysis are available from the authors on request.

${ }^{9}$ Bias-corrected Malmquist indices as well as their components were also calculated, but since their mean square error (MSE) was higher than the MSE of the original estimates in most of the cases ( $91 \%$ for MI, $97 \%$ for TE, $98 \%$ for TT under the assumption of the common frontier; $93 \%$ for MI and 97\% for TE and TT under the assumption of European and US frontiers) we do not report them here. The procedure for choosing which Malmquist estimator (and its components) to be used is based on Simar and Wilson (1999: 463).
} 
the fact that unity is not included between the lower and upper bounds of the confidence intervals expressed by Eq. (7).

Interestingly, a rise in TFP is registered on average for the whole European sample (1.4\% per year in the case of the common frontier method, $0.5 \%$ per year in the case of the region-specific frontier), which was mainly due to changes in technical efficiency (a catching up effect). At the same time, the productivity of American HEIs underwent a slight decline: a $1.4 \%$ drop when the global frontier is assumed and $0.2 \%$ with the country-specific frontier. Altogether, they experience an increase in technical changes and a decrease in technology development.

Table 3. Annual changes in productivity (MI), efficiency (TE) and technology (TT) - mean values of statistically significant ${ }^{*}$ indices by country for the period $2000-2010$

\begin{tabular}{|c|c|c|c|c|c|c|}
\hline & \multicolumn{3}{|c|}{ Common frontier } & \multicolumn{3}{|c|}{ European/US frontier } \\
\hline & MI & TE & TT & MI & TE & TT \\
\hline \multirow[t]{2}{*}{ AUSTRIA } & 0.991 & 1.014 & 0.963 & 0.973 & 0.971 & 0.991 \\
\hline & $(0.141)$ & $(0.179)$ & $(0.135)$ & $(0.136)$ & $(0.172)$ & $(0.091)$ \\
\hline \multirow[t]{2}{*}{ FINLAND } & 1.020 & 1.070 & 0.968 & 1.013 & 1.031 & 0.992 \\
\hline & $(0.222)$ & $(0.327)$ & $(0.145)$ & $(0.202)$ & $(0.269)$ & $(0.094)$ \\
\hline \multirow[t]{2}{*}{ GERMANY } & 1.020 & 1.051 & 0.995 & 1.017 & 1.027 & 1.007 \\
\hline & $(0.252)$ & $(0.257)$ & $(0.199)$ & $(0.248)$ & $(0.205)$ & $(0.178)$ \\
\hline \multirow[t]{2}{*}{ ITALY } & 1.052 & 1.122 & 0.956 & 1.036 & 1.069 & 0.979 \\
\hline & $(0.138)$ & $(0.163)$ & $(0.108)$ & $(0.114)$ & $(0.152)$ & $(0.103)$ \\
\hline \multirow[t]{2}{*}{ NETHERLANDS } & 1.050 & 1.076 & 1.011 & 1.044 & 1.048 & 1.016 \\
\hline & $(0.151)$ & $(0.184)$ & $(0.147)$ & $(0.160)$ & $(0.191)$ & $(0.153)$ \\
\hline \multirow[t]{2}{*}{ POLAND } & 1.012 & 1.027 & 0.995 & 1.004 & 1.017 & 0.995 \\
\hline & $(0.141)$ & $(0.180)$ & $(0.130)$ & $(0.132)$ & $(0.175)$ & $(0.114)$ \\
\hline \multirow[t]{2}{*}{ SPAIN } & 0.976 & 0.970 & 1.004 & 0.983 & 0.970 & 1.011 \\
\hline & $(0.122)$ & $(0.165)$ & $(0.112)$ & $(0.117)$ & $(0.147)$ & $(0.091)$ \\
\hline \multirow[t]{2}{*}{ SWEDEN } & 1.021 & 1.040 & 1.001 & 1.008 & 1.024 & 0.992 \\
\hline & $(0.219)$ & $(0.259)$ & $(0.126)$ & $(0.190)$ & $(0.224)$ & $(0.120)$ \\
\hline \multirow[t]{2}{*}{ SWITZERLAND } & 1.021 & 1.045 & 0.994 & 1.011 & 1.087 & 0.982 \\
\hline & $(0.096)$ & $(0.140)$ & $(0.121)$ & $(0.082)$ & $(0.099)$ & $(0.123)$ \\
\hline \multirow[t]{2}{*}{ UK } & 1.003 & 1.036 & 0.976 & 0.985 & 1.015 & 0.972 \\
\hline & $(0.134)$ & $(0.173)$ & $(0.124)$ & $(0.124)$ & $(0.172)$ & $(0.118)$ \\
\hline \multirow[t]{2}{*}{ Europe } & 1.014 & 1.044 & 0.984 & 1.005 & 1.021 & 0.990 \\
\hline & $(0.174)$ & $(0.208)$ & $(0.140)$ & $(0.163)$ & $(0.183)$ & $(0.125)$ \\
\hline \multirow[t]{2}{*}{ USA } & 0.986 & 1.028 & 0.958 & 0.998 & 1.006 & 0.992 \\
\hline & $(0.094)$ & $(0.154)$ & $(0.117)$ & $(0.088)$ & $(0.137)$ & $(0.090)$ \\
\hline
\end{tabular}

Note: ${ }^{*}$ significance at $10 \%$ level. Results based on the DEA model 1: three-input (total revenue, academic staff, students)/two-output model (publications, graduates). Mean values equal to geometrical mean of the sample. Standard deviations in parenthesis.

Source: own elaboration. 
Looking at the single European countries, the highest growth was experienced by Dutch and Italian HEIs (an average annual growth of around 5\% in the case of the common frontier). In both cases it was driven by technical efficiency changes. These are followed by Finnish, German, Swedish and Swiss institutions, with growth of around 2\% per year, again as a consequence of an increase in technical efficiency. Polish HEIs improved their productivity by around $1 \%$ annually on average and UK ones by $0.3 \%$. Finally, Austria and Spain are the only European countries with a decrease in productivity: a $1 \%$ annual decrease for Austria and 2.4\% for Spain is recorded. All of the indices (except for Spain and the US) are slightly lower when we consider European- and US-specific frontiers rather than the common one. In the extreme case of the UK, instead of an average annual growth of $0.3 \%$ we now obtain a $1.5 \%$ decline in productivity.

As already stated, the percentage of statistically significant indices is high. However, it is interesting to see the percentage of significant improvements versus significant deteriorations (Table A1 in Appendix). For most of the countries, the proportion of HEIs that experienced significant improvements is higher than the proportion of institutions with a productivity drop (e.g. in Italy $60 \%$ of all the Malmquist indices indicate a significant improvement while $29 \%$ show a productivity decline). This is also true for Europe as a whole. On the contrary, in the U.S. the percentage of observations with a drop in productivity is greater than the improvements. Similarly, in Austria, Spain and the UK, significant productivity drops outnumber productivity rises. However, the difference between European and US significant improvements and drops becomes less evident when we stick to the regional specific frontier.

A further confirmation of the different patterns in productivity changes between HEIs in Europe and the U.S. can be seen in Figure 3, where annual changes in TFP are graphically represented for the two subgroups over the period 2000-2010.

On average, the U.S. institutions achieved improvements in productivity only in 2000/2001 and 2008/2009; for the rest of the period the indices were below 1 , indicating

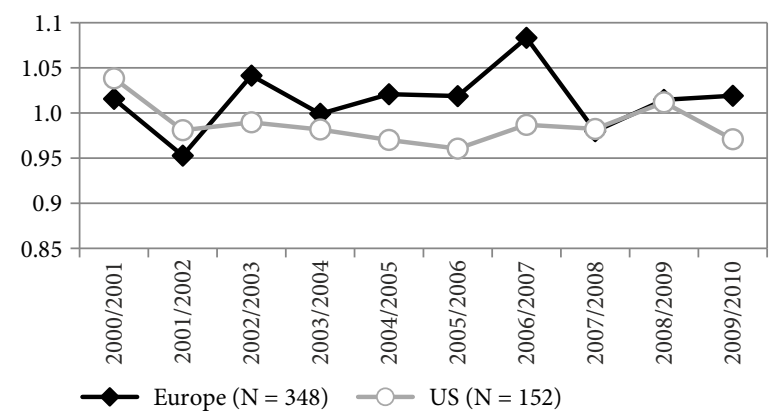

Notes: results based on Malmquist indexes that are statistically significant at $10 \%$ level. The results are based on DEA model 1: three inputs (expenditure, academic staff, students)/two outputs (publications, graduates); a common efficiency frontier is imposed. Mean values equal to geometrical mean of the sample.

Fig. 3. Annual changes in TFP (Malmquist indexes) in the period 2000-2010, U.S. and European samples Source: authors' elaboration 
a decline in TFP. On the contrary, in the European sample productivity decreased only in 2001/2002 and 2007/2008. A wider gap in productivity changes is concentrated in the years 2004-2007.

The specific results reported refer to the use of the three-input two-output DEA model, but a correlation matrix for the Malmquist indices obtained with different models is presented in the Appendix, and shows that they are qualitatively and quantitatively (Pearson scores) similar (Table A2 in Appendix).

\subsection{Determinants of TFP growth}

At this stage, TFP changes obtained through Malmquist indices are linked through a parametric panel data model with additional variables describing the source of financial resources (public versus non-public ones), the size of the institution and the level of development of the region the institution is located in. By doing this we are able to determine the factors crucial to promoting productivity gains in the context of public higher education. In the recent literature, emphasis is put on the importance of external sources in contributing to improve university efficiency (Bonaccorsi, Daraio 2007). Aghion et al. (2010) note that external sources of funding strengthen the autonomy of the university, and this in turn has a positive effect on the competitiveness of the institution. This is confirmed by Wolszczak-Derlacz and Parteka (2011), who in their two-step analysis find that government resources are negatively correlated with the efficiency of public HEIs in seven European countries (the more external funding from third parties, the greater efficiency). However, for American HEIs the relationship is not so clear. For example, according to the empirical analysis performed by Sav $(2012,2013)$ a higher share of state funding is associated with greater efficiency of public colleges (although without statistical significance when other factors are controlled for).

Next, we check the impact of location on the productivity growth of HEIs. The question is whether universities from economically advantaged regions can be expected to have superior performance (because they attract better staff and students or through cooperation with local business). Bonaccorsi and Daraio (2005) do not confirm the impact of locations in larger agglomerations on the level of education efficiency. Moreover, Agasisti and Pohl (2012) find that universities in economically disadvantaged regions gain efficiency more rapidly then those in advantaged ones. Finally, Varga and Horváth (2013) using a different methodology (a probit model applied to Europe-wide university data) confirm a positive association between institutional factors (such as university size, external funding, international embeddedness and university quality) and the probability of a university patenting, while regional factors (region size, concentration of public research, agglomeration of regional business services, regional technological output and the development of the regional innovation system) are correlated negatively.

The last determinant is connected with the size of the institutions. The question of whether bigger HEIs are more efficient and/or more productive relates to testing for economies of scale ${ }^{10}$. Bonaccorsi and Daraio (2005) in a thorough review of the literature dedi-

\footnotetext{
${ }^{10}$ The formal definition of an economy of scale refers to a decreasing cost per unit of production when the size of operations increases.
} 
cated to testing the existence of economies of scale in higher education show rather ambiguous results. Additionally, in their own analysis they find no support for size effects and even a weak decreasing return on research output - depending on the discipline analysed. On the contrary, Wolszczak-Derlacz and Parteka (2011) demonstrate that increasing unit size improves the efficiency of the institution. In a recent study by Bonaccorsi et al. (2014), size has a statistically significant impact on efficiency, but with an inverted $U$ shape.

Note that due to the use of DEA efficiency measures TFP growth encompasses general rises in productivity when multiple outputs of HEIs (teaching and research) are considered. The model to be estimated takes the following form:

$$
T F P_{i, t}=\alpha+\beta_{1} R E V_{-} G O V_{i, t}+\beta_{2} G D P_{n, t}+\beta_{3} \operatorname{Size}_{i, t}+\chi_{i}+v_{t}+u_{i t},
$$

where $i$ refers to a single HEI and $t$ denotes the time period. The dependent variables are TFP growths (calculated as in Eq. (5)). REV_GOV stands for the share of core funding out of total revenue, GDP indicates the real GDP per capita of the region where the university is located (the regional level is NUTS2 in the case of the European sample and the state in the case of the U.S.) and Size is measured by the number of students. Additionally, we include time dummies $\left(\mathrm{v}_{\mathrm{t}}\right)$ to incorporate time specific effects (e.g. due to the crisis or reforms) and in order to pick up any unmeasurable institutional effects, we add individual institution effects $\left(\chi_{i}\right)$.

The regression is estimated separately for the two subgroups: European and U.S. universities. As for the estimation strategy, we use a feasible generalized least squares (GLS) estimator with a heteroskedastic error structure. GLS allows for cross-sectional time-series linear models in the case of heteroskedasticity across panels. Table 4 presents the results when the Malmquist index based on the DEA model 1 is used as dependent variable. There are some notable differences between the results obtained for European and American HEIs. The upper panel of Table 4 presents the results when the Malmquist index is calculated on the basis of one common (global) frontier. The size of the unit seems to have a negative impact on TFP growth both for the European and American institutions (in the case of the American sample the parameter is not always statistically significant: columns 5 and 6). We need to remember that our dependent variable is growth in TFP - larger units can be less capable of increasing the growth of their productivity because they can be less elastic, more bureaucratic etc. However, this does not mean that larger universities are less efficient. In fact, when we employ DEA scores as the dependent variable we obtain a positive and statistically significant correlation between efficiency and size for both the European and American HEIs ${ }^{11}$.

In the case of the next variable analysed (GDP), we obtain different results for the two subsamples. When we consider European universities, we obtain a positive and statistically significant parameter: the greater the level of regional development, the higher the productivity growth of a given university is; while for the American sample the parameter is negative. The result for the U.S. can be explained by a convergence process across regions/states resulting in higher productivity growth of education institutions located in poorer states.

\footnotetext{
11 The results are available from the authors on request.
} 
Finally, the last variable analysed - government revenue - turns out to be negatively correlated with TFP growth for European HEIs: the more revenue from the government the lower the productivity growth. However, this relationship is different in the case of American HEIs - the share of government resources is positively associated with TFP growth. This dissimilar association between share of government resources and productivity for European and U.S. universities can be a result of different procedures for obtaining these funds in Europe and in the U.S., e.g. government resources when distributed as a lump sum (not depending on any performance indicators or open competition as is the case for American universities) act against productivity improvement.

The lower panel of Table 4 presents the results when the Malmquist indices are calculated on the basis of European/US frontiers. The results are similar to those obtained with the common frontier method, but the magnitude of the estimated coefficients and their statistical significance decreases. The difference is especially noteworthy in the case of the size parameter, which loses its statistical significance for American institutions. Because

Table 4. The determinants of TFP growth

Table 4A. Common frontier

\begin{tabular}{lcccccc}
\hline \multicolumn{5}{c}{ Europe } & \multicolumn{3}{c}{ US } \\
\hline & $(1)$ & $(2)$ & $(3)$ & $(4)$ & $(5)$ & $(6)$ \\
\hline Ln(Stud $)_{1, t}$ & $-0.045^{* *}$ & $-0.052^{* * *}$ & $-0.053^{* *}$ & $-0.051^{* *}$ & -0.016 & 0.001 \\
\hline & {$[0.018]$} & {$[0.018]$} & {$[0.021]$} & {$[0.020]$} & {$[0.021]$} & {$[0.023]$} \\
\hline Ln(GDPpc $)_{n, t}$ & $0.088^{* * *}$ & $0.057^{* * *}$ & & $-0.189^{* * *}$ & $-0.178^{* * *}$ \\
\hline & {$[0.015]$} & {$[0.018]$} & {$[0.034]$} & {$[0.035]$} \\
\hline Rev_Gov $_{i, t}$ & \multicolumn{7}{c}{$-0.139^{* * *}$} & & $0.057^{* *}$ \\
\hline & & {$[0.042]$} & & 1520 & 1517 \\
\hline $\mathrm{N}$ & 3371 & 2873 & 1520 &
\end{tabular}

Table 4B. European/US frontier

\begin{tabular}{lcccccc}
\hline \multicolumn{5}{c}{ Europe } & \multicolumn{3}{c}{ US } \\
\hline & $(1)$ & $(2)$ & $(3)$ & $(4)$ & $(5)$ & $(6)$ \\
\hline Ln(Stud $)_{I, t}$ & -0.023 & $-0.026^{\star}$ & $-0.034^{\star}$ & -0.007 & 0.004 & 0.014 \\
\hline & {$[0.016]$} & {$[0.016]$} & {$[0.019]$} & {$[0.020]$} & {$[0.021]$} & {$[0.022]$} \\
\hline Ln(GDPpc $)_{n, t}$ & & $0.027^{\star *}$ & 0.016 & & $-0.060^{\star}$ & -0.05 \\
\hline & {$[0.013]$} & {$[0.016]$} & & {$[0.034]$} & {$[0.034]$} \\
\hline Rev_Gov $_{i, t}$ & & $-0.088^{\star *}$ & & & $0.042^{\star}$ \\
\hline & & {$[0.036]$} & & 1520 & 1517 \\
\hline $\mathrm{N}$ & 3371 & 3371 & 2873 & 1520 & & $0.024]$ \\
\hline
\end{tabular}

Notes: Estimations performed using General Least Squares (GLS), with a full set of institution and time dummies. Standard errors are adjusted for heteroskedasticity. $\mathrm{p}<0.10,{ }^{* \star} \mathrm{p}<0.05$, ${ }^{\star * \star} \mathrm{p}<0.01^{\star}$. Source: own calculations. 
of this we will not draw strong conclusions regarding an association between the size of a given institution and its productivity growth as far as American units are considered.

The above-mentioned results are confirmed when we employ as dependent variable Malmquist indices obtained with alternative input/output specifications (DEA models described in Table 2). The negative size effect in the case of the European sample is also obtained when instead of student numbers we employ variables such as the number of total staff or the number of different faculties. However, the latter can also be an indication of a university's interdisciplinarity ${ }^{12}$. A final robustness check involves additional IV estimates correcting for potential endogeneity problems between TFP growth and government resources which are instrumented by their lags. The results of the first-differences panel data model are presented in Table A3 in Appendix. For the European sample, the negative correlation between growth in government revenue and TFP changes is confirmed - the coefficient now has a higher value, while the positive relation for American institutions is not statistically significant.

\section{Conclusions}

In this study, we have applied Malmquist methodology based on estimation of distance measures through DEA to a sample of 500 universities (in 10 European countries and the U.S.) over the period 2000 to 2010 in order to assess and compare their productivity. The main aim of this research was to evaluate changes in efficiency over time in universities in European countries and the U.S. and to assess the importance of university-specific factors in promoting productivity, while taking into account a possible different impact of these factors for European and American academia.

First, using non-parametric frontier techniques we measured changes in TFP adopting an output-oriented formulation of the DEA model. The baseline model included three inputs (total revenue, the number of academic staff, total students) and two outputs (the number of publications and graduates). We measured the productivity change with respect to a common frontier (considering the DEA analysis of European and U.S. institutions jointly), and secondly computing Malmquist indices separately for HEIs in Europe and the U.S. On average, a rise in TFP is registered for the whole European sample (strongest for Dutch and Italian HEIs), while the productivity of American HEIs evidenced a slight decline. Additionally, the heterogeneity of the productivity changes both within and between countries has been observed.

In the second stage of our analysis, we linked annual rates of TFP growth observed in single HEIs with individual characteristics describing their size, the development of their region and the structure of their finance (from government and non-government sources). For European universities, we found a negative impact of the size of the institution and the share of government resources on productivity growth, and a positive impact of regional development. American HEIs were characterised by a negative association between productivity growth and GDP and a positive association with the share of government resources out of total revenue.

\footnotetext{
$\overline{12}$ The detail results of the described robustness checks are available from the authors on request.
} 
Some constraints of this study need to be mentioned. First of all, the modelling of university production is not perfect (e.g. only teaching and research activities were taken into account, while the so-called third mission was not as it is difficult to measure; the discipline mix of universities was not incorporated etc.). As usual in such cross-countries studies, when one common database does not exist (e.g. at the European level) the comparability of data can be problematic, although extreme effort was made to ensure the correspondence and reliability of the data. Finally, it must be pointed out that although our database includes a high number of individual institutions (to the best of our knowledge our database is the most comprehensive one available in terms of number of institutions, variables and years covered) it cannot be treated as a representative sample, and as such the interpretations and conclusions above cannot be directly applied to the entire population of institutions and the whole higher education sector.

However, the study has confirmed the need to perform such an analysis and has shown that it can be helpful not only in assessing the productivity of HEIs but also in providing knowledge about the necessary changes and directions to achieve greater productivity, which is crucial if universities want to compete in an international environment.

\section{Acknowledgements}

Part of the paper was written when the author was a visiting scholar at University of California, Berkeley. The financial support of the Polish Ministry of Science and Higher Education under the programme "Mobility Plus" is gratefully acknowledged. The paper has benefited from the comments of participants of II Ogólnopolska Konferencja Badaczy Szkolnictwa Wyższego [Second National Conference of Higher Education Researchers], University of Poznan, December 2015, Workshop on Efficiency in Education, Lancaster University, September 2014, International Economic Meeting, University of Warsaw, July 2014 and from seminar participants at the University of California Berkeley, March 2014.

\section{References}

Agasisti, T.; Johnes, G. 2009. Beyond frontiers: comparing the efficiency of higher education decision making units across countries, Education Economics 17(1): 59-79.

http://dx.doi.org/10.1080/09645290701523291

Agasisti, T.; Pérez-Esparrells, C. 2010. Comparing efficiency in a cross-country perspective: the case of Italian and Spanish state universities, Higher Education 59(1): 85-103.

http://dx.doi.org/10.1007/s10734-009-9235-8

Agasisti, T.; Pohl, C. 2012. Comparing German and Italian public universities: convergence or divergence in the higher education landscape?, Managerial and Decision Economics 33: 71-85. http://dx.doi.org/10.1002/mde.1561

Aghion, P.; Dewatripont, M.; Hoxby, C.; Mas-Colell, A.; Sapir, A. 2010. The governance and performance of universities: evidence from Europe and the US, Economic Policy 25(61): 7-59. http://dx.doi.org/10.1111/j.1468-0327.2009.00238.x

Aguilera-Barchet, B. 2012. A higher education for the twenty-first century: European and US approaches, Centre for European Studies. 
Akviran, N. K. 2001. Investigating technical and scale efficiencies of Australian universities through data envelopment analysis, Socio-economic Planning Sciences 35: 57-80.

http://dx.doi.org/10.1016/S0038-0121(00)00010-0

Altbach, P. G.; Gumport, P. J.; Berdahl, R. O. 2011. American Higher Education in the Twenty-First Century: Social, Political, and Economic Challenges. $3^{\text {rd }}$ ed. Baltimore: The Johns Hopkins University Press.

Bonaccorsi A.; Daraio C. 2005. Exploring size and agglomeration effects on public research productivity, Scientometrics 63(1): 87-120. http://dx.doi.org/10.1007/s11192-005-0205-3

Bonaccorsi, A.; Daraio, C. (Eds.). 2007. Universities and strategic knowledge creation: specialization and performance in Europe. Cheltenham/Northampton, Massachusetts: Edward Elgar Publishing.

Bonaccorsi, A.; Daraio, C.; Simar, L. 2007. Efficiency and productivity in European universities: exploring trade-offs in the strategic profile, in A. Bonaccorsi, C. Daraio (Eds.). Universities and Strategic knowledge creation: specialization and performance in Europe. Cheltenham/Northampton, Massachusetts: Edward Elgar Publishing, 144-206. http://dx.doi.org/10.4337/9781847206848.00012

Bonaccorsi, A.; Daraio, C.; Simar, L. 2014. Efficiency and economies of scale and scope in European universities. A directional distance approach, Technical Report No. 8. Sapienza University of Rome.

Brennan, S.; Haelermans, C.; Ruggiero, J. 2014. Nonparametric estimation of education productivity incorporating nondiscretionary inputs with an application to Dutch schools, European Journal of Operational Research 234: 809-818. http://dx.doi.org/10.1016/j.ejor.2013.10.030

Caves, D. W.; Christensen, L. R.; Diewert, W. E. 1982. The economic theory of index numbers and the measurement of input, output, and productivity, Econometrica 50(6): 1393-1414. http://dx.doi.org/10.2307/1913388

Eurydice. 2015. National Student Fee and Support Systems in European Higher Education 2014/15.

Färe, R.; Grosskopf, S.; Lindgren, B.; Roos, P. 1992. Productivity change in Swedish pharmacies 19801989: a nonparametric Malmquist approach, Journal of Productivity Analysis 3: 85-102.

http://dx.doi.org/10.1007/978-94-017-1923-0_6

Färe, R.; Grosskopf, S.; Lovell, C. A. K. 1994. Production frontiers. Cambridge University Press.

Farrell, M. J. 1957. The measurement of productivity efficiency, Journal of The Royal Statistical Society. Series A (General) 120(3): 253-281. http://dx.doi.org/10.2307/2343100

Førsund, F. R.; Kalhagen, K. O. 1999. Efficiency and productivity of Norwegian colleges. Memorendum No 11/99. Department of Economics University of Oslo.

Johnes, J. 2004. Efficiency measurement, in G. Johnes, J. Johnes (Eds.) The International Handbook on the Economics of Education. Cheltenham: Edward Elgar, 613-742.

http://dx.doi.org/10.4337/9781845421694.00021

National Center for Education Statistics. 2015. Digest of Education Statistics, 2013. Institute of Education Sciences. U.S. Department of Education, Washington, DC.

Nazarko, J.; Šaparauskas, J. 2014. Application of DEA method in efficiency evaluation of public higher education institutions, Technological and Economic Development of Economy 20(1): 25-44. http://dx.doi.org/10.3846/20294913.2014.837116

OECD. 2002. Frascati manual. Proposed standard practice for surveys on research and experimental development. OECD, Paris.

Panagiotis, R. 2014. Meta-regression analysis of higher education productivity growth studies. Master's thesis, University of Macedonia [online], [cited 20 November 2014]. Available from Internet: https://dspace.lib.uom.gr/dspace/bitstream/2159/16057/3/RavanosPanagiotisMsc2014.pdf

Parteka, A.; Wolszczak-Derlacz, J. 2013. Dynamics of productivity in higher education - cross-European evidence based on bootstrapped Malmquist indices, Journal of Productivity Analysis 40(1): 67-82. http://dx.doi.org/10.1007/s11123-012-0320-0 
Sav, G. T. 2012. Stochastic cost frontier and inefficiency estimates of public and private universities: does government matter?, International Advances in Economic Research 18(2): 187-198. http://dx.doi.org/10.1007/s11294-012-9353-4

Sav, G. T. 2013. Effects of financial source dependency on public university operating efficiencies: data envelopment single-stage and Tobit two-stage evaluations, Review of Economics \& Finance 3: 63-73.

Simar, L.; Wilson, P. W. 1999. Estimating and bootstrapping Malmquist indices, European Journal of Operational Research 115: 459-471. http://dx.doi.org/10.1016/S0377-2217(97)00450-5

Staiger, D.; Stock, J., 1997. Instrumental variables regression with weak instruments, Econometrica 65: 557-586. http://dx.doi.org/10.2307/2171753

Unesco-IUS/OECD/Eurostat data collection manual. 2004. Data collection on education systems. Paris: OECD.

Varga, A.; Horváth, M. 2013. Institutional and regional factors behind university patenting in Europe: an exploratory spatial analysis using EUMIDA data, in $35^{\text {th }}$ DRUID Celebration Conference 2013, 17-19 June 2013, Barcelona, Spain.

Wilson, P. W. 2008. FEAR 1.0: A software package for frontier efficiency analysis with R, Socio-Economic Planning Sciences 42: 247-254. http://dx.doi.org/10.1016/j.seps.2007.02.001

Wolszczak-Derlacz, J.; Parteka, A. 2011. Efficiency of European public higher education institutions: a two-stage multicountry approach, Scientometrics 89(3): 887-917. http://dx.doi.org/10.1007/s11192-011-0484-9

Worthington, A. C. 2001. An empirical survey of frontier efficiency measurement techniques in education, Education Economics 9(3): 245-268. http://dx.doi.org/10.1080/09645290110086126

Yang, H.; Pollitt, M. 2012. Incorporating undesirable outputs into Malmquist TFP indices with an unbalanced data panel of Chinese power plants, Applied Economics Letters 19: 227-283.

http://dx.doi.org/10.1080/13504851.2011.572843

\section{APPENDIX}

Table A1. Percentage of total statistically significant indices, percentage of HEIs registering statistically significant improvements and declines in productivity, efficiency and technology

\begin{tabular}{lcccccccccc}
\hline \multicolumn{7}{c}{ Common frontier } \\
\hline country & $\begin{array}{c}\text { \% of } \\
\text { st sign }\end{array}$ & $\begin{array}{c}\text { \% of } \\
\text { improv. }\end{array}$ & $\begin{array}{c}\text { \% of } \\
\text { decline }\end{array}$ & $\begin{array}{c}\text { \% of st } \\
\text { sign }\end{array}$ & $\begin{array}{c}\text { TE of } \\
\text { improv. }\end{array}$ & $\begin{array}{c}\text { \% of } \\
\text { decline }\end{array}$ & $\begin{array}{c}\text { \% of } \\
\text { st. sign }\end{array}$ & $\begin{array}{c}\% \text { of } \\
\text { improv. }\end{array}$ & $\begin{array}{c}\text { \% of } \\
\text { decline }\end{array}$ \\
\hline AUT & 90 & 42 & 48 & 59 & 33 & 26 & 39 & 15 & 25 \\
\hline FIN & 88 & 46 & 42 & 51 & 31 & 20 & 45 & 19 & 26 \\
\hline GER & 89 & 51 & 39 & 59 & 33 & 26 & 49 & 25 & 24 \\
\hline IT & 89 & 60 & 29 & 62 & 50 & 12 & 50 & 14 & 36 \\
\hline NLD & 77 & 50 & 27 & 40 & 31 & 9 & 51 & 21 & 30 \\
\hline POL & 87 & 47 & 40 & 37 & 22 & 15 & 37 & 17 & 20 \\
\hline ESP & 88 & 34 & 54 & 59 & 26 & 34 & 45 & 22 & 23 \\
\hline SWE & 89 & 48 & 41 & 65 & 38 & 28 & 58 & 25 & 33 \\
\hline CHN & 82 & 49 & 33 & 31 & 19 & 12 & 31 & 12 & 19 \\
\hline UK & 88 & 41 & 47 & 62 & 38 & 24 & 60 & 22 & 38 \\
\hline Europe & 88 & 47 & 41 & 57 & 35 & 22 & 50 & 21 & 29 \\
\hline USA & 86 & 35 & 51 & 61 & 41 & 20 & 63 & 18 & 44 \\
\hline & & & & & & & & & \\
\hline
\end{tabular}


End of Table A1

\begin{tabular}{|c|c|c|c|c|c|c|c|c|c|}
\hline \multicolumn{10}{|c|}{ Common frontier } \\
\hline \multicolumn{10}{|c|}{ European/US frontier } \\
\hline AUT & 95 & 41 & 54 & 69 & 31 & 38 & 48 & 25 & 24 \\
\hline FIN & 91 & 48 & 42 & 57 & 32 & 25 & 51 & 20 & 31 \\
\hline GER & 87 & 47 & 39 & 54 & 32 & 22 & 44 & 21 & 24 \\
\hline IT & 91 & 60 & 31 & 64 & 44 & 20 & 54 & 22 & 32 \\
\hline NLD & 81 & 51 & 30 & 44 & 32 & 12 & 35 & 15 & 20 \\
\hline POL & 88 & 45 & 43 & 42 & 24 & 18 & 38 & 19 & 20 \\
\hline ESP & 83 & 35 & 48 & 60 & 24 & 36 & 51 & 26 & 25 \\
\hline SWE & 88 & 43 & 45 & 62 & 34 & 28 & 53 & 21 & 32 \\
\hline $\mathrm{CHN}$ & 88 & 52 & 36 & 24 & 20 & 4 & 19 & 6 & 13 \\
\hline UK & 86 & 34 & 52 & 55 & 28 & 26 & 58 & 21 & 37 \\
\hline Europe & 87 & 44 & 43 & 56 & 31 & 25 & 50 & 21 & 28 \\
\hline USA & 87 & 43 & 44 & 56 & 27 & 29 & 55 & 28 & 27 \\
\hline
\end{tabular}

Source: own elaboration.

Table A2. Pairwise correlations between Malmquist indexes based on different DEA models (Pearson coefficients)

\begin{tabular}{|c|c|c|c|c|c|c|c|c|c|c|c|c|}
\hline \multirow[b]{3}{*}{ Modell } & \multicolumn{6}{|c|}{ Malmquist indices } & \multicolumn{6}{|c|}{ Malmquist unbiased indices } \\
\hline & \multicolumn{3}{|c|}{ Common frontier } & \multicolumn{3}{|c|}{ Country frontier } & \multicolumn{3}{|c|}{ Common frontier } & \multicolumn{3}{|c|}{ Country frontier } \\
\hline & 1 & 2 & 3 & 4 & 5 & 6 & 7 & 8 & 9 & 10 & 11 & 12 \\
\hline 1 & 1.00 & & & & & & & & & & & \\
\hline 2 & 0.70 & 1.00 & & & & & & & & & & \\
\hline 3 & 0.88 & 0.64 & 1.00 & & & & & & & & & \\
\hline 4 & 0.95 & 0.65 & 0.85 & 1.00 & & & & & & & & \\
\hline 5 & 0.66 & 0.94 & 0.61 & 0.67 & 1.00 & & & & & & & \\
\hline 6 & 0.83 & 0.58 & 0.95 & 0.88 & 0.61 & 1.00 & & & & & & \\
\hline 7 & 0.98 & 0.69 & 0.84 & 0.90 & 0.65 & 0.77 & 1.00 & & & & & \\
\hline 8 & 0.70 & 0.99 & 0.63 & 0.65 & 0.91 & 0.57 & 0.71 & 1.00 & & & & \\
\hline 9 & 0.88 & 0.64 & 0.98 & 0.84 & 0.61 & 0.90 & 0.87 & 0.64 & 1.00 & & & \\
\hline 10 & 0.93 & 0.64 & 0.82 & 0.98 & 0.66 & 0.85 & 0.91 & 0.65 & 0.83 & 1.00 & & \\
\hline 11 & 0.66 & 0.91 & 0.60 & 0.67 & 0.99 & 0.60 & 0.65 & 0.91 & 0.60 & 0.67 & 1.00 & \\
\hline 12 & 0.84 & 0.58 & 0.92 & 0.89 & 0.61 & 0.98 & 0.81 & 0.58 & 0.91 & 0.89 & 0.61 & 1.00 \\
\hline
\end{tabular}

Notes: Malmquist unbiased indexes are obtained by bootstrap methods following Simar and Wilson (1999). All Pearson coefficients are significant at 1\% level. Model specification as in Table 2.

Source: own elaboration. 
Table A3. The determinants of TFP growth - IV estimations of the first-difference model

\begin{tabular}{lcccc}
\hline & \multicolumn{2}{c}{ Common frontier } & \multicolumn{2}{c}{ European/US frontier } \\
\hline & Europe & US & Europe & US \\
\hline$\Delta \operatorname{Ln}(\text { Stud })_{I, t}$ & $(1)$ & $(2)$ & $(3)$ & $(4)$ \\
\hline & $-0.161^{* *}$ & -0.096 & $-0.130^{*}$ & -0.230 \\
\hline$\Delta \operatorname{Ln}(\mathrm{GDPpc})_{n, t}$ & {$[0.078]$} & {$[0.088]$} & {$[0.073]$} & {$[0.278]$} \\
\hline & 0.074 & $-0.366^{* *}$ & -0.01 & -0.053 \\
\hline$\Delta$ Rev_Gov $_{i, t}$ & {$[0.074]$} & {$[0.163]$} & {$[0.069]$} & {$[0.146]$} \\
\hline & $-0.860^{* *}$ & 0.094 & $-0.867^{* *}$ & 0.034 \\
\hline $\mathrm{N}$ & {$[0.420]$} & {$[0.193]$} & {$[0.393]$} & {$[0.172]$} \\
\hline Under-identification & 2298 & 1216 & 2298 & 1216 \\
\hline Weak identification & 0.000 & 0.000 & 0.000 & 0.000 \\
\hline Sargan (p-value) & 69.725 & 98.808 & 69.725 & 98.808 \\
\hline
\end{tabular}

Notes: Estimations performed using IV estimates, government ravenous (Rev_Gov $\mathrm{Gov}_{\mathrm{i}, \mathrm{f}}$ ) treated as endogenous variable and instrumented by its first and second lags. The estimates carried in STATA with the use of xtivreg2 command and first-differences panel data models. The figures reported for the under-identification test are the p-values and refer to the Kleibergen-Paap rk LM test statistic, where a rejection of the null indicates that the instruments are not under-identified. The weak identification test refers to the Kleibergen-Paap Wald rk F statistic test for the presence of weak instruments. As a "rule of thumb" the statistic should be at least 10 for weak identification not to be considered a problem (Staiger, Stock 1997).

Statistically significant at ${ }^{\star * *} 1,{ }^{\star *} 5,{ }^{\star} 10$ percent level.

Source: own calculations.

Joanna WOLSZCZAK-DERLACZ. She is an Assistant Professor at Gdańsk University of Technology, Poland (Faculty of Management and Economics). In 2015, she obtained habilitation for two monothematic series of publications, one entitled: "Efficiency and productivity of higher education institutions". In the academic year 2013/2014, she was conducting her research at the University of California, Berkeley; she was also a beneficiary of the Max Weber Fellowship at the European University Institute in Florence (2007/2008). Her research interests embrace theory of economic convergence and empirical analysis of efficiency and productivity of higher education institutions. 